\title{
Decrease of Wine Volatile Aroma Esters by Oxidation
}

\author{
M. Patrianakou and I.G. Roussis* \\ Laboratory of Food Chemistry, Department of Chemistry, University of Ioannina, 45110 Greece
}

Date of submission for publication: February 2013

Date of acceptance for publication: July 2013

Key words: Wine, ester, oxidation

\begin{abstract}
The effect of oxidation on the levels of wine volatile aroma esters was studied. Chardonnay wine was bottled either in the presence of nitrogen or air in the headspace. Moreover, Fe II was added to the wine and the bottles were closed in the presence of air. Absorbance values were recorded at $420 \mathrm{~nm}$ (browning index), while volatile esters were evaluated during storage using SPME/GC-MS. During wine storage of up to nine months, wines bottled in the presence of air exhibited higher browning indexes and lower levels of several esters, such ethyl acetate, isoamyl acetate, ethyl hexanoate, ethyl octanoate and ethyl decanoate, in comparison to wines bottled under nitrogen. Addition of Fe II led to higher browning indexes and lower levels of several esters during wine storage. In addition, Fe II was added along with $\mathrm{H}_{2} \mathrm{O}_{2}$ to Chardonnay wine and the bottles were closed in the presence of air. These additions led to wines with higher browning indexes and lower levels of several esters during wine storage up to 40 days. The present results demonstrate that wine volatile aroma esters can be decreased by oxidation under semi-oxidative and forced oxidative conditions. As a result, oxidation should be taken into account in the decrease of aroma esters during wine storage.
\end{abstract}

\section{INTRODUCTION}

Several wine volatile compounds, such as esters, acids, terpenes and alcohols, are transformed during wine ageing and storage, leading to changes in wine aroma (Jackson, 2008).

Some basic aromas perceived in wine are from esters. During fermentation, ester formation is strongly dependent upon yeast strain and fermentation temperature (Killian \& Ough, 1979; Papathanasiou et al., 2006). The hydrolysis of esters into acids and alcohols and the formation of esters from acids and alcohols take place during wine ageing. Subsequently, the concentrations of esters in wine during ageing and storage are related to their different hydrolysisesterification equilibria (Ramey \& Ough, 1980; Makhotkina \& Kilmartin, 2012).

Decreases in acetate esters and many ethyl esters have been observed during the ageing of wines, while other ethyl esters have increased or remained stable (Lambropoulos \& Roussis, 2007; Roussis et al., 2007; Oliveira et al., 2008; Papadopoulou \& Roussis, 2008). Similar behaviour of esters has been observed during the oxidative storage of wines (Ferreira et al., 1997; Roussis et al., 2005).

Oxidation of white and red wines is a well-known problem in winemaking, particularly the oxidative spoilage of young wines. The first step in wine oxidation is characterised by the transformation of aroma compounds. This leads to a loss of the characteristic aromas of wines, the formation of new aromas characteristic of older wines or atypical aromas associated with wine spoilage, and to oxidative browning (Singleton, 1987; Fernadez-Zurnbano et al., 1995; Vaimakis \& Roussis, 1996).

Recent knowledge about wine oxidation reveals the role played by transition metals and free radicals. Reactive oxygen species (ROS) are formed during oxygen reduction in the presence of metals. At the $\mathrm{pH}$ of wine, Fe II reduces oxygen to hydrogen peroxide, which in the presence of Fe II is converted to hydroxyl radicals by the so-called Fenton reaction. Under wine oxidation conditions, phenolic compounds are among the primary reactants with oxygen, and more precisely with ROS, which are better oxidants than oxygen. Consequently, the oxidation of phenolic compounds in wine initiates a series of chemical transformations. Semiquinone radicals and quinones are formed, while oxygen is reduced to hydrogen peroxide in the presence of transition metals, such as Fe II. Moreover, quinones are formed by direct oxidation by Fe III under acidic conditions. Quinones are unstable and may undergo further reactions. These reactions may cause pigment formation, for instance condensation reactions that form coloured products with high molecular weight. As electrophiles, quinones can spontaneously react directly with nucleophilic compounds, including some phenolics, sulphydryl compounds and amines. In the process, dimers or polymers are produced, which can form new diphenols. The regenerated o-diphenols will be oxidised renewably, ultimately accelerating the polymerisation reaction of phenols (Singleton, 1987; 
Danilewicz, 2003; Waterhouse \& Laurie, 2006; Li et al., 2008; Oliveira et al., 2011).

Hydroxyl radicals are a very strong and non-selective oxidant, and are considered to oxidise almost all wine components (Waterhouse \& Laurie, 2006).

Sulphur dioxide is widely used in winemaking. It does not react directly with oxygen, but with the oxygen-reduced form, hydrogen peroxide. In this way, sulphur dioxide can inhibit aldehyde formation by competing for hydrogen peroxide. Sulphur dioxide also plays an important role in reducing quinones back to their phenolic form (Danilewicz, 2003; Danilewicz et al., 2008; Ellias \& Waterhouse, 2010).

The aim of this research was to study the effect of oxidation on the levels of wine volatile aroma esters.

\section{MATERIALS AND METHODS}

The $\mathrm{FeCl}_{2} \cdot 4 \mathrm{H}_{2} \mathrm{O}$ and $30 \% \mathrm{H}_{2} \mathrm{O}_{2}$ were purchased from Merck (Darmstadt, Germany). Chardonnay white wine, of the 2009 vintage, was obtained from the Glinavos winery (Zitsa, Greece). Alcohol was determined with a hydrometer, $\mathrm{pH}$ with a $\mathrm{pH}$ meter, total acidity by volumetric analysis, free sulphide by the Ripper method, and total phenolics according to the Folin-Ciocalteu method, using gallic acid as a standard. The alcohol content was $13 \%$ vol, pH was 3.3, free $\mathrm{SO}_{2} 42 \mathrm{mg} / \mathrm{L}$, total $\mathrm{SO}_{2} 62 \mathrm{mg} / \mathrm{L}$ and total phenolics 314 $\mathrm{mg} / \mathrm{L}$.

In all experiments glass bottles of $250 \mathrm{~mL}$ capacity, similar in shape to wine bottles, were used. Bottles were closed using metal caps and a manually operated closure machine. In the samples treated with nitrogen, $200 \mathrm{~mL}$ of wine were put into the bottles, which then were closed under gas nitrogen (nitrogen was added in the headspace). In the control samples, $200 \mathrm{~mL}$ of wine were put into the bottles, which then were closed without any precaution (in the presence of air). In samples with $\mathrm{Fe}$ II addition, $\mathrm{FeCl}_{2} \cdot 4 \mathrm{H}_{2} 0$ was added directly to the wine at $0.14 \mathrm{mM}$. Two hundred $\mathrm{mL}$ of wine were put in the bottles, which then were closed without any precaution (in the presence of air). After 0, 60, 120 and 270 days of storage at $18^{\circ} \mathrm{C}$, bottles were taken and wine samples were analysed.

In samples with $\mathrm{Fe}$ II- $\mathrm{H}_{2} \mathrm{O}_{2}$ addition, $\mathrm{FeCl}_{2} \cdot 4 \mathrm{H}_{2} 0$ was added directly to the wine, followed by the addition of 1 $\mathrm{mL}$ of solution of $\mathrm{H}_{2} \mathrm{O}_{2}$ in the wine. The final concentration of $\mathrm{FeCl}_{2} \cdot 4 \mathrm{H}_{2} 0$ was $0.14 \mathrm{mM}$, and that of $\mathrm{H}_{2} \mathrm{O}_{2}$ was 0.84 $\mathrm{mM}$. Two hundred $\mathrm{mL}$ of wine were put in the bottles, which then were closed without any precaution (in the presence of air). After 0,20 and 40 days of storage at $18^{\circ} \mathrm{C}$, bottles were taken and wine samples were analysed. The control was prepared as described above. All wine samples were analysed by solid phase microextraction (SPME), along with gas chromatography-mass spectrometry (GC-MS). A Carbowax ${ }^{\mathrm{TM}}$ Divinylbenzene 65 um fibre (Supelco, Bellefonte, PA, USA) was used for the absorption of volatiles.

Two $\mathrm{mL}$ of each wine sample and $50 \mu \mathrm{L}$ of internal standard in 10\% ethanol (4-methyl-1-pentanol, $5 \mathrm{mg} / \mathrm{L}$ in final solution) were transferred into a $4 \mathrm{~mL}$ screw-capped glass vial with a Teflon-rubber septum (red, $12 \mathrm{~mm}$, Sun-Sri, Rockwood, TN, USA). The contents were stirred for $15 \mathrm{~min}$ at $40^{\circ} \mathrm{C}$. A constant length of the fibre then was exposed to the headspace for another $20 \mathrm{~min}$ at $40^{\circ} \mathrm{C}$ without stirring. Desorption of volatiles took place at $250^{\circ} \mathrm{C}$ using a $0.75 \mathrm{~mm}$ ID liner (Supelco, Bellefonte, PA, USA) for $5 \mathrm{~min}$. Split mode was used, and the split ratio was $2: 1$.

GC-MS analysis was carried out on an HP 5973 quadrupole mass spectrometer, directly coupled to an HP 6890 gas chromatograph. MS conditions were as follows: source temperature: $230^{\circ} \mathrm{C}$, quadrupole temperature: $150^{\circ} \mathrm{C}$, transfer line temperature: $270^{\circ} \mathrm{C}$. Acquisition was performed in electron impact (EI) mode $(70 \mathrm{eV})$ by 2.02 scans s$^{-1}$, and the mass range was 29 to $400 \mathrm{~m} / \mathrm{z}$. Solvent delay was applied up to $6.0 \mathrm{~min}$ to avoid the ethanol peak. A DB-5 fused-silica capillary column was used ( $60 \mathrm{~m} \times 0.32 \mathrm{~mm}$ internal diameter, $1.0 \mu \mathrm{m}$ film thickness, J\&W Scientific, Folsom, CA, USA). The flow rate of the helium carrier gas was $1.1 \mathrm{~mL} \mathrm{~min}^{-1}$. The oven temperature was programmed at $40^{\circ} \mathrm{C}$ for $5 \mathrm{~min}$, and then raised to $260^{\circ} \mathrm{C}$ at a rate of $5^{\circ} \mathrm{C} / \mathrm{min}$, and it was held at $260^{\circ} \mathrm{C}$ for $10 \mathrm{~min}$. All peaks were identified by comparing mass spectra to those obtained from the Wiley library (Wiley 275; J. Wiley \& Sons Ltd., West Sussex, England).

The identification of many peaks was confirmed with mass spectra and retention times of standard compounds determined under the same analysis conditions. Authentic standards used were ethyl acetate, isoamyl acetate, hexyl acetate, 2-phenyl ethyl acetate, ethyl butanoate, ethyl hexanoate, ethyl octanoate, ethyl decanoate and ethyl dodecanoate (Merck, Darmstadt, Germany). Semiquantitative data were expressed in milligrams per litre [(area of compound/area of internal standard) $\cdot$ concentration of internal standard]. Each experiment was repeated three times and the results reported are the means of the three trials. The one-way analysis of variance (ANOVA), using the Bonferroni test at a level of significance of $\mathrm{P}<0.05$, was used for statistical analysis (SPSS 17.0). When two groups were compared, the paired test was used instead of the ANOVA.

\section{RESULTS AND DISCUSSION}

The effect of oxidation on the levels of volatile esters during storage of white wine was studied. In the first experimental section, Chardonnay wine was bottled in the presence of either nitrogen or air in the headspace. Moreover, Fe II was added to the wine and the bottles were closed in the presence of air. The results of the volatile esters, along with those of the browning index (absorbance at $420 \mathrm{~nm}$ ) of the experimental wines are presented in Table 1 . At $\mathrm{t}=0$, all experimental wines exhibited similar concentrations of any volatile ester, and similar absorbance at $420 \mathrm{~nm}$.

Wines bottled under nitrogen exhibited a higher browning index after 270 days of storage, indicating that the wines had been subjected to oxidation to some extent. The oxidation may have been due to dissolved oxygen or to oxidative species present in the wine. After 60, 120 and 270 days of storage, the wine exhibited lower concentrations of several esters, such as ethyl acetate, isoamyl acetate, ethyl hexanoate, ethyl octanoate and ethyl decanoate. These decreases can be attributed to ester hydrolysis, while oxidation may also have had an impact.

During storage, wines bottled in the presence of air exhibited higher browning indexes than those bottled under nitrogen, indicating that they had been oxidised to a greater 


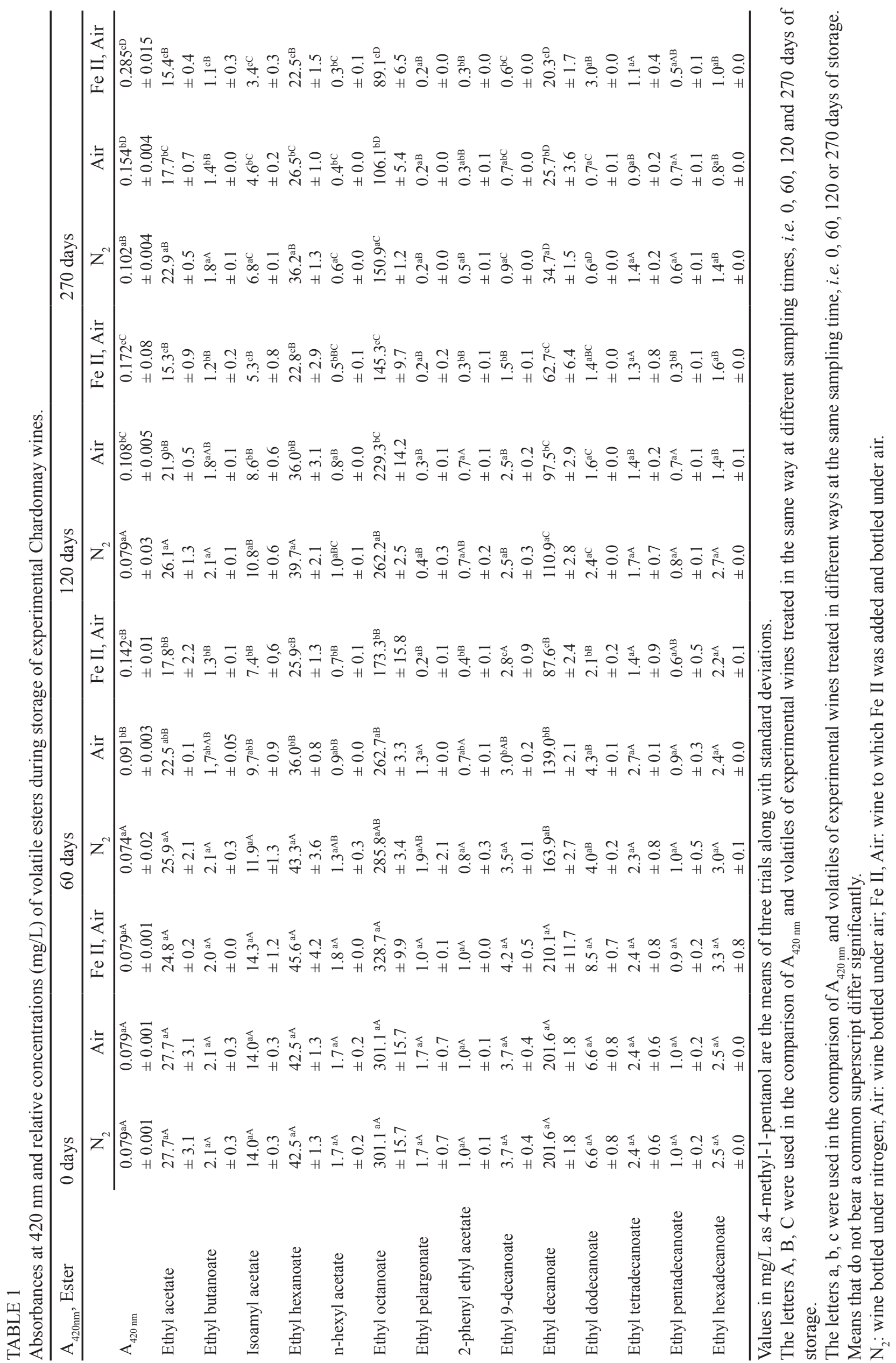


extent. In a similar manner, air-bottled wines exhibited lower concentrations of several aroma esters than nitrogenbottled wines. The above indicate than wine aroma esters can be decreased by oxidation. It should be noted that two hundred $\mathrm{mL}$ of wine were put in bottles of $250 \mathrm{~mL}$ capacity. Subsequently, the large headspace indicated that the conditions were semi-oxidative.

At $t=60,120$ and 270 days of storage, wines containing Fe II (air bottled) exhibited higher A420 nm and lower concentrations of most esters in comparison with air-bottled wine. The higher A420 nm of the wines containing Fe II indicates their higher degree of browning and oxidation. The lower concentrations of most esters in wine containing $\mathrm{Fe}$ II in comparison to the controls indicate that their decrease can be attributed to oxidation. The above can be explained by the formation of hydroxyl radicals. It is accepted that, at the $\mathrm{pH}$ of wine, Fe II transforms oxygen to hydrogen peroxide and then to hydroxyl radicals. Hydroxyl radicals are a very strong and non-selective oxidant and can oxidise many wine constituents. The higher degree of browning can be attributed to the formation of polyphenol quinones, since Fe II plays a significant role in their formation (Danilewicz, 2003; Waterhouse \& Laurie, 2006; Li et al., 2008; Oliveira et al., 2011). The decrease of esters may be due to direct attack of hydroxyl radicals, since they can oxidise saturated compounds, or by ester interaction with polyphenol quinones. It should be noted that the Fe II added to wine is about 10 times higher than that typically found in wine, namely 1 $\mathrm{mg} / \mathrm{L}$. This indicates that forced oxidisation conditions were used.
In the second experimental section, $\mathrm{FeCl}_{2} \cdot 4 \mathrm{H}_{2} 0$ and $\mathrm{H}_{2} \mathrm{O}_{2}$ were added to Chardonnay wine and the bottles were closed in the presence of air. Wine bottled in the presence of air (control) was used for comparison.

The results of the volatile esters along with those of the browning index (absorbance at $420 \mathrm{~nm}$ ) of the experimental wines are presented in Table 2 . At $\mathrm{t}=0$, the addition of Fe II along with hydrogen peroxide did not change the concentration of any volatile esters or of the absorbance at $420 \mathrm{~nm}$. The control wine exhibited similar absorbances at $420 \mathrm{~nm}$ during wine storage for up to 40 days. In contrast, the addition of Fe II along with $\mathrm{H}_{2} \mathrm{O}_{2}$ to wine led to higher $\mathrm{A}$ $420 \mathrm{~nm}$, showing a higher degree of browning and oxidation. In the control, the concentrations of esters did not change during wine storage. On the contrary, the addition of Fe II along with $\mathrm{H}_{2} \mathrm{O}_{2}$ to wine led to lower concentrations of most esters during wine storage. The higher degree of browning and the decrease in esters can be attributed to oxidation initiated by the formation of hydroxyl radicals, as discussed above. It should be noted that the levels of Fe II and $\mathrm{H}_{2} \mathrm{O}_{2}$ added to wine were extreme, indicating that forced oxidisation conditions were used. The present results indicate that wine esters can be oxidised. Changes in the concentrations of wine esters during storage could be related to their hydrolysis-esterification equilibria (Ramey \& Ough, 1980; Makhothika \& Kilmartin, 2012). The present results indicate that ester oxidation should be taken into account during wine storage.

Of the esters studied, higher losses were observed for ethyl decanoate, ethyl octanoate, ethyl hexanoate, ethyl

TABLE 2

Absorbances at $420 \mathrm{~nm}$ and relative concentrations $(\mathrm{mg} / \mathrm{L})$ of volatile esters during storage of experimental Chardonnay wines.

\begin{tabular}{|c|c|c|c|c|c|c|}
\hline $\mathrm{A}_{420 \mathrm{~nm}}$, Ester & $\begin{array}{l}\text { Control } \\
0 \text { days }\end{array}$ & $\begin{array}{l}\mathrm{Fe} \mathrm{II-} \mathrm{H}_{2} \mathrm{O}_{2} \\
0 \text { days }\end{array}$ & $\begin{array}{l}\text { Control } \\
20 \text { days }\end{array}$ & $\begin{array}{l}\mathrm{Fe} \mathrm{II}-\mathrm{H}_{2} \mathrm{O}_{2} \\
20 \text { days }\end{array}$ & $\begin{array}{l}\text { Control } \\
40 \text { days }\end{array}$ & $\begin{array}{l}\mathrm{Fe} \mathrm{II-} \mathrm{H}_{2} \mathrm{O}_{2} \\
40 \text { days }\end{array}$ \\
\hline $\mathrm{A}_{420 \mathrm{~nm}}$ & $0.079^{\mathrm{aA}} \pm 0.001$ & $0.080^{\mathrm{aA}} \pm 0.001$ & $0.080^{\mathrm{aA}} \pm 0.003$ & $0.117^{\mathrm{bB}} \pm 0.002$ & $0.089^{\mathrm{aA}} \pm 0.001$ & $0.137^{\mathrm{bC}} \pm 0.004$ \\
\hline Ethyl acetate & $27.7^{\mathrm{aA}} \pm 3.1$ & $24.2^{\mathrm{aA}} \pm 1.0$ & $27.4^{\mathrm{aA}} \pm 1.4$ & $18.7^{\mathrm{bB}} \pm 0.6$ & $27.5^{\mathrm{aA}} \pm 1.1$ & $15.3^{\mathrm{bC}} \pm 1.5$ \\
\hline Ethyl butanoate & $2.1^{\mathrm{aA}} \pm 0.3$ & $1.9^{\mathrm{aA}} \pm 0.2$ & $2.1^{\mathrm{aA}} \pm 0.1$ & $1.8^{\mathrm{aAB}} \pm 0.2$ & $2.1^{\mathrm{aA}} \pm 0.0$ & $1.3^{\mathrm{bB}} \pm 0.2$ \\
\hline Isoamyl acetate & $14.3^{\mathrm{aA}} \pm 1.2$ & $14.0^{\mathrm{aA}} \pm 0.0$ & $9.6^{\mathrm{aA}} \pm 0.9$ & $8.4^{\mathrm{bA}} \pm 0.2$ & $11.0^{\mathrm{aA}} \pm 0.4$ & $6.8^{\mathrm{bB}} \pm 0.3$ \\
\hline Ethyl hexanoate & $42.5^{\mathrm{aA}} \pm 1.3$ & $39.8^{\mathrm{aA}} \pm 6.2$ & $41.7^{\mathrm{aA}} \pm 1,0$ & $35.7^{\mathrm{bAB}} \pm 6.5$ & $41.4^{\mathrm{aA}} \pm 4.7$ & $25.1^{\mathrm{bB}} \pm 2.2$ \\
\hline n-hexyl acetate & $1.7^{\mathrm{aA}} \pm 0.2$ & $1.5^{\mathrm{aA}} \pm 0.5$ & $1.2^{\mathrm{aA}} \pm 0.1$ & $0.8^{\mathrm{aAB}} \pm 0.1$ & $1.0^{\mathrm{aB}} \pm 0.1$ & $0.7^{\mathrm{aB}} \pm 0.1$ \\
\hline Ethyl octanoate & $301.1^{\mathrm{aA}} \pm 15.7$ & $319.5^{\mathrm{aA}} \pm 17.0$ & $299.6^{\mathrm{aA}} \pm 11.4$ & $251.0^{\mathrm{bB}} \pm 8.8$ & $297.6^{\mathrm{aA}} \pm 23.6$ & $176.4^{\mathrm{bC}} \pm 16.6$ \\
\hline Ethyl pelargonate & $1.7^{\mathrm{aA}} \pm 0.7$ & $1.8^{\mathrm{aA}} \pm 0.4$ & $0.8^{\mathrm{aA}} \pm 0.2$ & $1.1^{\mathrm{aA}} \pm 0.1$ & $1.0^{\mathrm{aA}} \pm 0.6$ & $0.4^{\mathrm{bA}} \pm 0.3$ \\
\hline 2-phenyl ethyl acetate & $1.0^{\mathrm{aA}} \pm 0.1$ & $1.0^{\mathrm{aA}} \pm 0.3$ & $0.7^{\mathrm{aA}} \pm 0.0$ & $0.7^{\mathrm{aA}} \pm 0.2$ & $0.7^{\mathrm{aA}} \pm 0.1$ & $0.5^{\mathrm{aB}} \pm 0.1$ \\
\hline Ethyl 9-decanoate & $3.7^{\mathrm{aA}} \pm 0.4$ & $3.8^{\mathrm{aA}} \pm 0.6$ & $3.0^{\mathrm{aA}} \pm 1.2$ & $2.9^{\mathrm{aB}} \pm 0.4$ & $3.3^{\mathrm{aA}} \pm 0.1$ & $1.9^{\mathrm{bC}} \pm 0.1$ \\
\hline Ethyl decanoate & $201.6^{\mathrm{aA}} \pm 1.8$ & $203.0^{\mathrm{aA}} \pm 21.0$ & $194.9^{\mathrm{aA}} \pm 7.8$ & $145.6^{\mathrm{bB}} \pm 2.3$ & $172.0^{\mathrm{aB}} \pm 5.1$ & $99.4^{\mathrm{bC}} \pm 7.1$ \\
\hline Ethyl dodecanoate & $6.6^{\mathrm{aA}} \pm 0.8$ & $7.3^{\mathrm{aA}} \pm 1.8$ & $5.5^{\mathrm{aA}} \pm 0.3$ & $3.5^{\mathrm{bA}} \pm 2.4$ & $5.1^{\mathrm{aA}} \pm 0.6$ & $3.0^{\mathrm{bA}} \pm 0.2$ \\
\hline Ethyl tetradecanoate & $2.4^{\mathrm{aA}} \pm 0.6$ & $2.3^{\mathrm{aA}} \pm 0.8$ & $3.3^{\mathrm{aA}} \pm 0.2$ & $2.8^{\mathrm{aA}} \pm 1.0$ & $2.7^{\mathrm{aA}} \pm 0.1$ & $0.9^{\mathrm{bA}} \pm 0.4$ \\
\hline Ethyl pentadecanoate & $1.0^{\mathrm{aA}} \pm 0.2$ & $0.9^{\mathrm{aA}} \pm 0.2$ & $1.7^{\mathrm{aB}} \pm 0.2$ & $1.5^{\mathrm{aA}} \pm 0.5$ & $1.2^{\mathrm{aAB}} \pm 0.2$ & $0.3^{\mathrm{bB}} \pm 0.2$ \\
\hline Ethyl hexadecanoate & $2.5^{\mathrm{aA}} \pm 0.0$ & $2.8^{\mathrm{aAB}} \pm 0.9$ & $3.8^{\mathrm{aA}} \pm 0.4$ & $4.3^{\mathrm{aA}} \pm 1.1$ & $3.5^{\mathrm{aA}} \pm 1.4$ & $0.8^{\mathrm{aB}} \pm 0.5$ \\
\hline
\end{tabular}

Values, $\mathrm{mg} / \mathrm{L}$ as 4-methyl-1-pentanol, are the means of three trials along with standard deviations.

The letters A, B, C were used in the comparison of $\mathrm{A}_{420 \mathrm{~nm}}$ and volatiles of experimental wines treated in the same way at different sampling times, i.e. 0,20 and 40 days of storage.

The letters a, b, c were used in the comparison of $\mathrm{A}_{420 \mathrm{~nm}}$ and volatiles of experimental wines treated in different ways at the same sampling time, i.e. 0,20 or 40 days of storage.

Means that do not bear a common superscript differ significantly.

Control: wine bottled under air; $\mathrm{Fe}$ II- $\mathrm{H}_{2} \mathrm{O}_{2}$ : wine to which Fe II and $\mathrm{H}_{2} \mathrm{O}_{2}$ were added and bottled under air. 
acetate and isoamyl acetate, while they were at much higher concentrations than the others. This is consistent with the statement that hydroxyl radicals can oxidise wine components in proportion to their concentration (Waterhouse \& Laurie, 2006). Ethyl hexanoate, ethyl octanoate and ethyl decanoate are the most important wine ethyl esters and play a significant role in the fruity notes of wines. Ethyl acetate at low levels, $<50 \mathrm{mg} / \mathrm{L}$, adds complexity to wine fragrance, whereas above $150 \mathrm{mg} / \mathrm{L}$ it is likely to give a sour-vinegar offodour, and isoamyl acetate has a banana-like scent (Jackson, 2008). Losses of these five esters under semi-oxidative and forced oxidative conditions indicate that oxidation should be taken into account in the decrease in fruity aroma during wine storage. However, further work is needed to evaluate the contribution of hydrolysis and oxidation to the decrease in aroma esters during wine storage.

\section{CONCLUSIONS}

The present results demonstrate that wine volatile aroma esters can be decreased by oxidation, under semi-oxidative and forced oxidative conditions. Subsequently, oxidation should be taken into account in the decrease in aroma esters during wine storage.

\section{LITERATURE CITED}

Danilewicz, J.D., 2003. Review of reaction mechanisms of oxygen and proposed intermediate reduction products in wine: Central role of iron and copper. Am. J. Enol. Vitic. 54, 73-85.

Danilewicz, J.D., Seccombe, J.T. \& Whelan, J., 2008. Mechanism of interaction of polyphenols, oxygen, and sulfur dioxide in model wine and wine. Am. J. Enol. Vitic. 59, 128-136.

Ellias, R.J. \& Waterhouse, A.L., 2010. Controlling the Fenton reaction in wine. J. Agric. Food Chem. 58, 1699-1707.

Fernadez-Zurbano, P., Ferreira, V., Rena, C., Escudero, A., Serrano, F. \& Cacho, J., 1995. Prediction of oxidative browning in white wines as a function of their chemical composition. J. Agric. Food Chem. 43, 28132817

Ferreira, V., Escudero, A., Fernandez, P. \& Cacho, J.F., 1997. Changes in the profile of volatile compounds in wines stored under oxygen and their relationship with the browning process. Z. Leb.- Unters. und- Forsch. A 205, 392-396.

Jackson, R.S., 2008 ( $3^{\text {rd }}$ ed). Wine science, principles and applications. Academic Press-Elsevier, Burlington, USA.
Killian, E. \& Ough, C.S., 1979. Fermentation esters formation and retention as affected by fermentation temperature. Am. J. Enol. Vitic. 30, 301-305.

Lambropoulos I. \& Roussis, I.G., 2007. Inhibition of the decrease of volatile esters and terpenes during storage of a white wine and a model wine medium by caffeic acid and gallic acid. Food Res. Intern. 40, 176-181.

Li H., Guo, A. \& Wang, H., 2008. Mechanisms of oxidative browning of wine. Food Chem. 108: 1-13.

Makhotkina, O. \& Kilmartin, P.A., 2012. Hydrolysis and formation of volatile esters in New Zealand Sauvignon blanc wine. Food Chem. 135, 486-493.

Oliveira, C.M., Ferreira, A.C.S., De Freitas, V. \& Silva, A.M.S., 2011. Oxidation mechanisms occurring in wines. Food Res. Intern. 44, 1115-1126.

Oliveira, J.M., Oliveira, P., Baumes, R.L. \& Maia, O., 2008. Changes in aromatic characteristics of Loureiro and Alvarinho wines during maturation. J. Food Compos. Anal. 21, 695-707.

Papadopoulou, D. \& Roussis, I.G., 2008. Inhibition of the decrease of volatile esters and terpenes during storage of a white wine and a model wine medium by glutathione and N-acetyl-cysteine. Intern. J. Food Sci. Technol. 43, 1053-1057.

Papathanasiou, I., Selvagini, R., Servili, M., Vaughan-Martini, A. \& Roussis, I.G., 2006. Winemaking ability of wild yeast strains and comparative volatile profiles of wines fermented at $12^{\circ}$ or $20^{\circ} \mathrm{C}$. Food Sci. Technol. Res. 12, 194-198.

Ramey, D.D. \& Ough, C.S., 1980. Volatile ester hydrolysis or formation during storage of model solutions and wines. J. Agric. Food Chem. 28, 928 934.

Roussis, I.G., Lambropoulos, I. \& Papadopoulou, D., 2005. Inhibition of the decline of volatile esters and terpenols during oxidative storage of Muscatwhite and Xinomavro-red wine by caffeic acid and N-acetyl-cysteine. Food Chem. 93, 485-492.

Roussis, I.G., Lambropoulos, I. \& Tzimas, P., 2007. Protection of volatiles in a wine with low sulfur dioxide by caffeic acid or glutathione. Am. J. Enol. Vitic. 58, 274-278.

Singleton, V.L., 1987. Oxygen with phenols and related reactions in musts, wines and model systems: Observations and practical implications. Am. J. Enol. Vitic. 38, 69-77.

Vaimakis, V. \& Roussis, I.G., 1996. Must oxygenation together with glutathione addition in the oxidation of white wine. Food Chem. 57, 419422.

Waterhouse, A.L. \& Laurie, V.F., 2006. Oxidation of wine phenolics: A critical evaluation and hypotheses. Am. J. Enol. Vitic. 57, 306-313. 